\title{
Pain response of resistance training of the paravertebral musculature under radiotherapy in patients with spinal bone metastases - a randomized trial
}

\author{
Harald Rief ${ }^{*}$, Thomas Welzel', Georg Omlor ${ }^{3}$, Michael Akbar $^{3}$, Thomas Bruckner ${ }^{2}$, Stefan Rieken ${ }^{1}$, \\ Matthias F Haefner ${ }^{1}$, Ingmar Schlampp ${ }^{1}$, Alexandros Gioules ${ }^{1}$ and Jürgen Debus ${ }^{1}$
}

\begin{abstract}
Background: To compare pain response outcomes for patients with spinal bone metastases treated with resistance training of the spinal musculature versus passive physical therapy during radiotherapy (RT).

Methods: In this randomized trial, 60 consecutive patients were treated from September 2011 until March 2013 within one of the two groups: resistance training (Arm A) or passive physical therapy (Arm B) with thirty patients in each group during RT. The course of pain according to visual analog scale (VAS), concurrent medication, and oral morphine equivalent dose (OMED) were assessed at baseline, three months, and six months after RT. Pain response was determined using International Bone Consensus response definitions.

Results: The course of VAS in the intervention group (Arm A) was significantly lower both during and after RT ( $A \cup C, p<.001$ ). The use of analgetic medication showed the same result, with significantly fewer analgetics being necessary both during and after RT in arm A ( $p<.001)$. In the course of time, the OMED decreased in arm A, but increased in arm B. After 6 month, 72.2\% of patients in arm A, and 22.2\% in arm B were responders $(p=.014)$.

Conclusion: Our trial demonstrated that guided isometric resistance training of the paravertebral muscles can improve pain relief over a 6-months period in patients with stable spinal metastases. Importantly, the intervention was able to reduce OMED as well as concomitant pain medication. The trial is registered in Clinical trial identifier NCT 01409720 (http://www.clinicaltrials.gov/) since $2^{\text {nd }}$ of August 2011.
\end{abstract}

Keywords: Bone metastases, Spine, Physical exercise, Pain response, Isometric muscle training, Palliative radiotherapy

\section{Background}

The spine is the most common site of bone metastases $[1,2]$. Bone metastases are a major clinical concern and cause severe pain, pathological fractures, spinal cord compression, hypercalcaemia with a significant decrease in quality of life [3]. Pain remains the most frequent symptom and the most important factor impairing the mobility and quality of life in patients with bone metastases [4]. Radiotherapy (RT) is a well-established non-

\footnotetext{
* Correspondence: harald.rief@med.uni-heidelberg.de

'Department of Radiation Oncology, University Hospital of Heidelberg, Im Neuenheimer Feld 400, Heidelberg 69120, Germany

Full list of author information is available at the end of the article
}

pharmacological effective treatment for the alleviation of pain from spinal metastases $[5,6]$. Other therapeutic options used to treat pain in addition to RT involve analgetics, systemic therapy, bisphosphonates, and minimal invasive surgery [3]. For these reasons, pain relief is an important clinical challenge and represents the primary goal of any therapy aiming to manage bone metastases [7]. Due to the potentially raised risk of pathological fractures, physicians have so far refrained from initiating forms of intervention involving sport exercises in patients with bone metastases, and there are no specifically exercise-related therapeutic measures involving isometric muscle training described in the literature in 
connection with bone metastases. Relating to tumor patients of any primary, there are numerous indications of the positive effect of targeted resistance training measures regarding pain and mobility $[4,8,9]$. Accordingly the effect of muscle-training exercises as an adjunct to RT in patients with bone metastases is still unknown.

The underlying concept of this randomized study is to compare the pain response of an isometric resistance training regimen of the paravertebral muscles as an adjunct to RT vs. RT alone in patients with spinal bone metastases. The objective may be seen as the integration of a combination therapy in palliative-care patients to reduce the primary symptom in cases of spinal bone metastases.

\section{Methods}

\section{Subjects and recruitment}

From September 2011 until March 2013, 80 consecutive patients with a histologically confirmed cancer of any primary and solitary or multiple bone metastases of the thoracic or lumbar segments of the vertebral column or of the os sacrum were screened in the Radiooncology Department of the Heidelberg University Clinic. Initially all patients were diagnosed as having painful bone metastases requiring RT. Inclusion criteria were an age of 18 to 80 years, a Karnofsky performance score $[10] \geq 70$, written consent to participate, and already initiated bisphosphonate therapy. The patients were subjected to a staging of their vertebral column within the context of the CT designed to plan the radiation schedule prior to enrolment into the trial. In this examination metastases in the thoracic and lumbar spine were classified as "stable" or "unstable". Patients with stable vertebral-body lesions were included. Out of 80 patients considered eligible, 15 patients were excluded due to unstable metastases, and five patients declined to participate in the study. 60 patients fulfilled the inclusion and were enrolled into the trial (Figure 1). The study was approved by the Heidelberg Ethics Committee (Nr. S-316/2011).

\section{Design, randomized allocation, and procedures}

This is a randomized, controlled, explorative intervention trial to compare pain response of a resistance training program for strengthening the paravertebral muscles in patients with bone metastases as an adjunct to RT. Patients in the control group conducted passive physical therapy in the form of respiratory exercises. A block randomization approach with block size 6 was used to ensure that the two groups were balanced. After baseline measurements, the patients with stable bone metastases were assigned to the respective treatment arms on a 1:1 basis according to the randomization list. The randomization procedure was

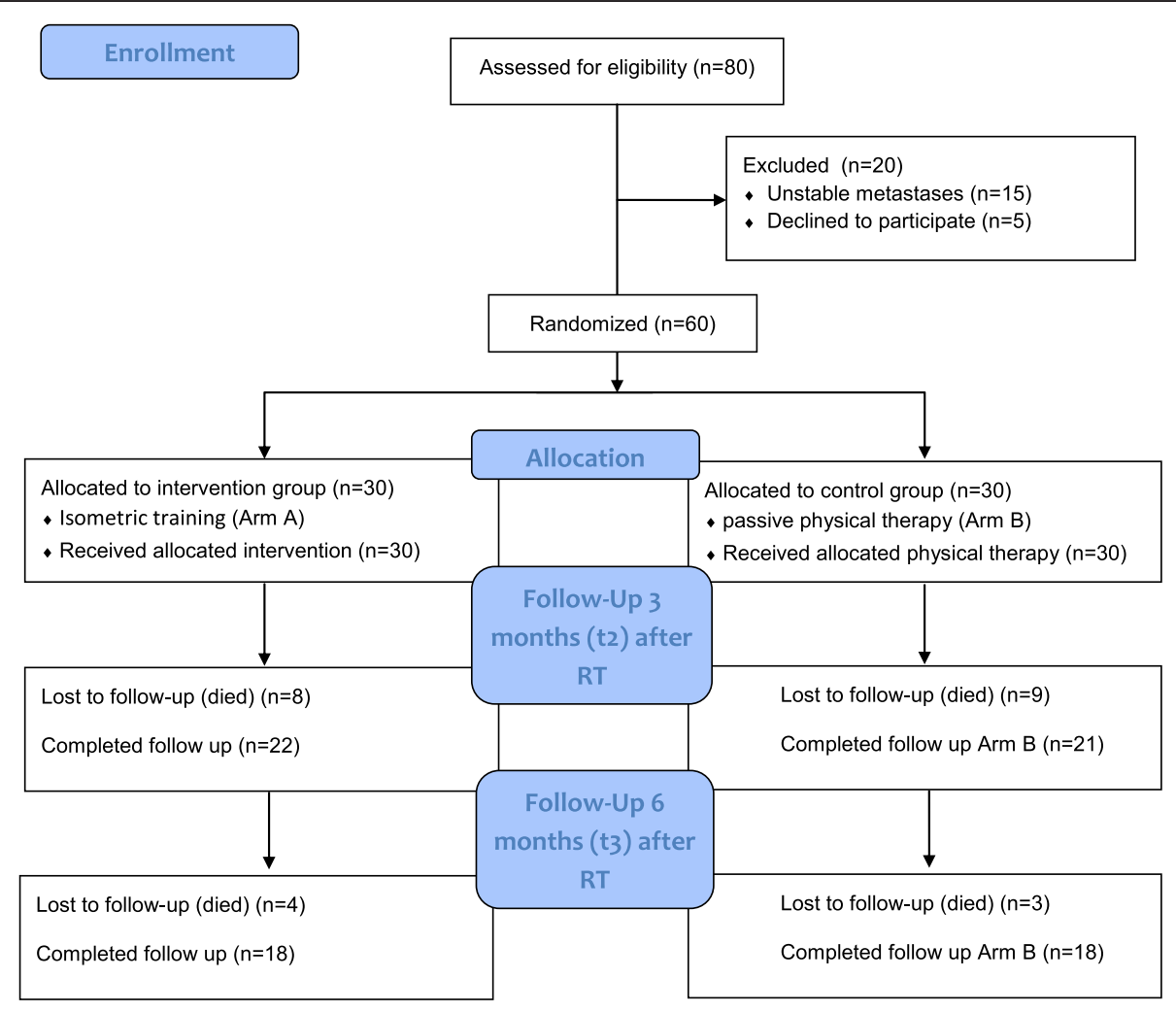

Figure 1 Flow of participants through the trial. 
carried out by a central office. Arm A (intervention group, resistance training) and in Arm B (control group, passive physical therapy) each consisted of 30 patients. The target parameters were measured at the start of radiotherapy $\left(\mathrm{t}_{0}\right)$, end of RT $\left(t_{1}\right)$, after twelve weeks $\left(t_{2}\right)$, and after six month $\left(t_{3}\right)$. The target parameters comprise the documentation of visual analog scale (VAS), neuropathic pain, oral morphine equivalent dose (OMED), concurrent medication, and the recording of patient-specific data. VAS and concurrent medication were documented daily for twelve weeks, and once after 6 month. VAS values following RT were recorded as the mean value for the week. In addition, the basic pain medication and concomitant medication from the start of RT until twelve weeks after RT were recorded daily and also six months after RT. During the therapy the values were documented by the study staff; subsequently

Table 1 Patient characteristics at baseline

\begin{tabular}{|c|c|c|c|c|c|}
\hline & & \multicolumn{2}{|c|}{ Intervention group $(n=30)$} & \multicolumn{2}{|c|}{ Control group $(n=30)$} \\
\hline & & $\mathrm{n}$ & $\%$ & $\mathrm{n}$ & $\%$ \\
\hline Age (years) & Mean (SD) & $61.3(10.1)$ & & $64.1(10.9)$ & \\
\hline \multirow[t]{2}{*}{ Gender } & Male & 14 & 46.7 & 19 & 63.3 \\
\hline & Female & 16 & 53.3 & 11 & 36.7 \\
\hline \multicolumn{2}{|c|}{ Karnofsky-index (median, range) } & \multicolumn{2}{|l|}{$80(70-100)$} & \multicolumn{2}{|l|}{$80(70-100)$} \\
\hline \multicolumn{6}{|l|}{ Primary site } \\
\hline & Lung cancer & 12 & 40.0 & 8 & 26.6 \\
\hline & Breast cancer & 5 & 16.7 & 6 & 20.1 \\
\hline & Prostate cancer & 5 & 16.7 & 9 & 30.1 \\
\hline & Melanoma & 1 & 3.3 & 1 & 3.3 \\
\hline & Renal cancer & 1 & 3.3 & 2 & 6.7 \\
\hline & Other & 6 & 20.1 & 4 & 13.4 \\
\hline \multicolumn{6}{|c|}{ Localization metastases } \\
\hline & Thoracic & 17 & 56.7 & 14 & 46.7 \\
\hline & Lumbar & 9 & 30.0 & 13 & 43.3 \\
\hline & Thoracic and lumbar & 2 & 6.7 & 2 & 6.7 \\
\hline & Sacrum & 2 & 6.7 & 1 & 3.3 \\
\hline \multicolumn{6}{|c|}{ Number metastases } \\
\hline & Mean (range) & $1.4(2-4)$ & & $1.7(1-5)$ & \\
\hline & Solitary & 22 & 73.3 & 18 & 60.0 \\
\hline & Multiple & 8 & 26.7 & 12 & 40.0 \\
\hline \multicolumn{6}{|l|}{ Type of metastases } \\
\hline & Mixed & 2 & 6.7 & 2 & 6.7 \\
\hline & Osteoblastic & 9 & 30.0 & 10 & 33.3 \\
\hline & Osteolytic & 19 & 63.3 & 18 & 60.0 \\
\hline \multicolumn{6}{|c|}{ Distant metastases at baseline } \\
\hline & Visceral & 12 & 40.0 & 5 & 16.7 \\
\hline & Brain & 3 & 10.0 & 3 & 10.0 \\
\hline & Lung & 7 & 23.3 & 4 & 13.3 \\
\hline & Tissue & 8 & 26.7 & 6 & 20.0 \\
\hline \multicolumn{2}{|l|}{ Hormonotherapy } & 10 & 33.3 & 16 & 53.3 \\
\hline \multicolumn{2}{|l|}{ Immunotherapy } & 7 & 23.3 & 5 & 16.7 \\
\hline \multicolumn{2}{|l|}{ Chemotherapy } & 25 & 83.3 & 20 & 66.7 \\
\hline \multicolumn{2}{|l|}{ Ataractics } & 4 & 13.3 & 2 & 6.7 \\
\hline \multicolumn{2}{|l|}{ NSAR } & 19 & 63.3 & 23 & 76.7 \\
\hline \multicolumn{2}{|l|}{ Opioids } & 11 & 36.7 & 13 & 43.3 \\
\hline
\end{tabular}

Abbreviation: SD standard deviation. 
the patients themselves continued the documentation in the form of a pain diary. Neuropathic pain was also recorded. The opioid analgetics were converted into an oral morphine equivalent dose (OMED). Non-opioid analgetics were also recorded. The data of the patient records were collected by the authors. Patient characteristics are shown in Table 1.

\section{Study interventions}

The interventions commenced on the same day as RT and were performed on each day of RT treatment (Monday through Friday) over a two-week period, independent of the number of fractions. During the two-week RT period, the patients in the resistance training group (Arm A) performed the exercises under guidance of a physiotherapist. The patients were then instructed to practice the training in their homes three times a week and continued the resistance training themselves until the last investigation after six months. The resistance training lasted approx. $30 \mathrm{~min}$, the physical therapy (Arm B) approx. 15 min. Since the site of the bone metastases differed from patient to patient, three different exercises were enacted to ensure an even isometric resistance training of the muscles along the entire vertebral column. The patients of the control group received physical therapy in the form of respiratory exercises also for a period of two weeks. A detailed report of the intervention and its application has already been published [11].

\section{Measures of the endpoint}

The endpoint was pain response, defined according to the International Bone Consensus response categories by Chow et al. [12] as complete response (CR), partial response (PR), pain progression (PP), and stable pain (SP) at three and six months after RT. The pain was documented on the visual analog scale (range 0-100). Complete response was defined as VAS $=0$ at treated site with no concomitant increase in analgetic intake (stable or reducing analgetics in daily oral morphine equivalent dose). Partial response was defined as pain reduction of 2 or more at the treated site without analgetic increase, or analgetic reduction of $25 \%$ or more from baseline without an increase in pain. Pain progression was defined as increase in pain score of 2 or more above baseline at the treated site with stable OMED, or an increase of $25 \%$ or more in OMED compared with baseline with the pain score stable or 1 point above baseline. Any response not covered by the complete response, partial response, or pain progression definitions was called "stable pain" [13]. Responders were defined as CR + PR, non-responders as PP + SP.

\section{Radiotherapy}

RT was performed in the Radiooncology Department of the Heidelberg University Clinic. After virtual simulation was performed to plan the radiation schedule, RT was carried out over a dorsal photon field of the 6MV energy range. PTV covered the specific vertebral body affected as well as the ones immediately above and below. In Arm A 24 patients $(80 \%)$ were treated with $10 \times 3 \mathrm{~Gy}$, three patients $(10 \%)$ with $14 \times 2.5 \mathrm{~Gy}$, and three patients $(10 \%)$ with $20 \times 2$ Gy. In Arm B the dose fractions for 28 patients $(93.3 \%)$ were $10 \times 3 \mathrm{~Gy}$, for one patient $(3.3 \%)$ $14 \times 2.5 \mathrm{~Gy}$, and for one patient (3.3\%) $20 \times 2 \mathrm{~Gy}$. The median individual dose in all patients was 3 Gy (range 2-3 Gy), the median total dose 30 Gy (range 20-35 Gy). The individual and total doses were decided separately for each individual patient, depending on the histology, the patient's general state of health, and on the current staging and the corresponding prognosis.

\section{Sample calculation and statistical analysis}

The total number of patients undergoing RT in the radiation oncology department of the Heidelberg University Clinic for metastatic processes in the vertebral column in

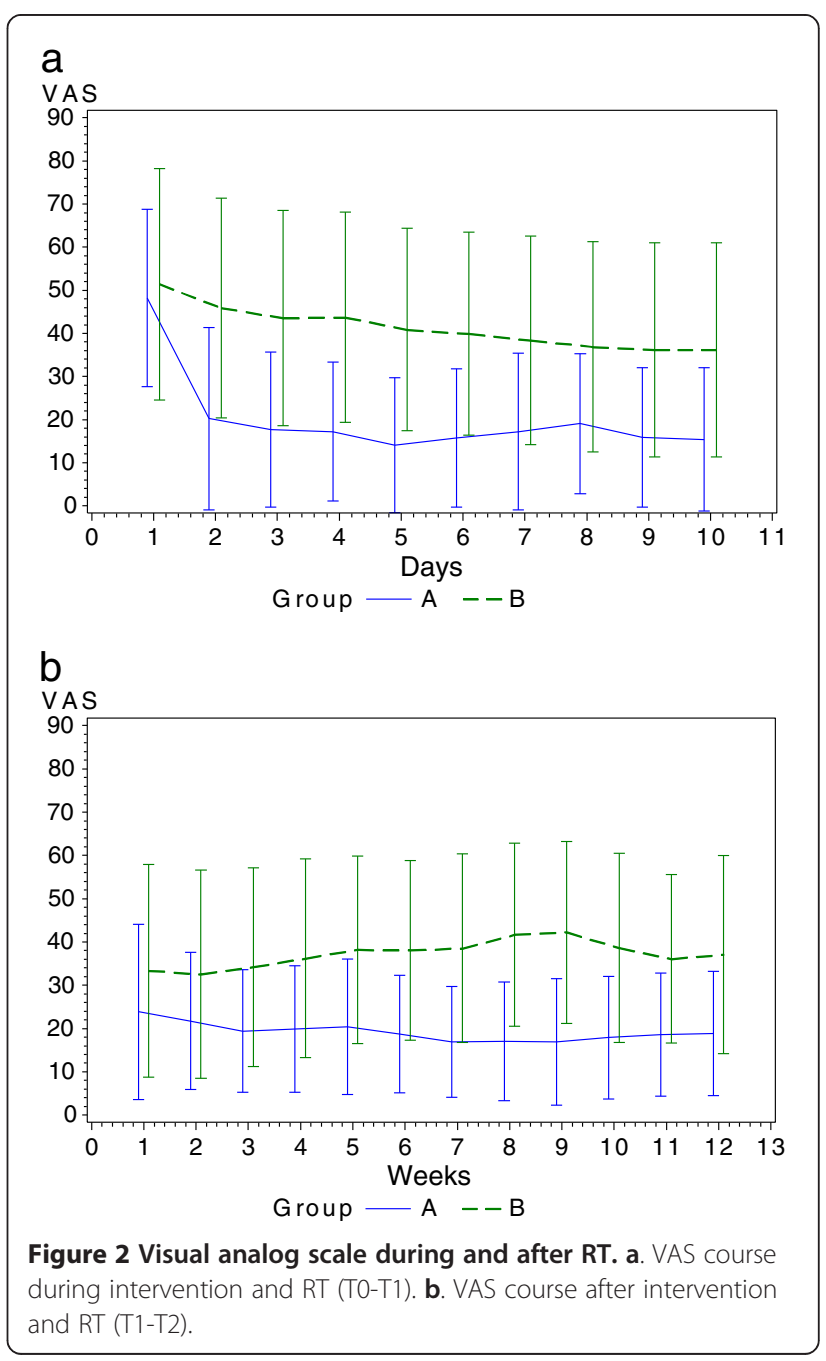


the recruitment period is approx. 120 , about 90 of whom shall fulfill the inclusion criteria. On account of the explorative character of this study, it was not possible to estimate the total number of cases; with a scheduled number of 30 patients per group, it will, however, be possible to detect a standardized mean-value effect of 0.8 with a power of $80 \%$ and an significance level of $5 \%$. All variables were analyzed descriptively by tabulation of the measures of the empirical distributions. According to the scale level of the variables, means and standard deviations or absolute and relative frequencies, respectively, were reported. Additionally, for variables with longitudinal measurements, the time courses of individual patients and summarized by treatment groups. Descriptive p-values of the corresponding statistical tests comparing the treatment groups will be given. The VAS was adjusted for concurrent medication. Analysis of covariance (ANOVA) with repeated measurements, with group as factor, time (days during RT, weeks after RT), and pain medications as covariance were done. Area under the curve was divided by number of visits per patient. Wilcoxon test was used to detect possible differences between groups. Graphical visualization includes boxplots and means course over time.

\section{Results}

The mean follow-up was 6.3 months for both groups. During the trial there were no adverse events. All surviving patients completed all surveys. Eight patients (26.7\%) in Arm A died within the first twelve weeks following RT, additional 4 patients (13.3\%) died within 6 months due to tumor progression. In Arm B, 9 patients died (30.0\%) within 3 months, and 3 further patients $(10.0 \%)$ within 6 months. Mortality did not differ between groups.

In arm A, NSAR were taken by $63.3 \%(n=19)$ and opioid analgetics by $36.7 \%(\mathrm{n}=11)$ of the patients. In $\operatorname{arm} B, 76.7 \%(n=23)$ of the patients took NSAR and $43.3 \%(n=13)$ opioids. During the resistance training in arm A $30 \%(n=9)$ of the patients reported resting pain and $46.7 \%(n=14)$ pain upon movement; four of these patients $(13.3 \%)$ were forced to take relief medication.

The course of VAS in the intervention group was significantly lower both during and after RT (AUC, p <.001) (Figure 2a, 2b). The taking of relief medication showed the same result, with significantly fewer analgetics being necessary both during and after RT in arm A $(\mathrm{p}<.001)$ (Table 2).

In the course of time, the OMED decreased in arm A, but increased in arm B. After three months a positive trend in favor of arm A was discernible, and after six months the OMED was significantly lower $(p=.018)$ (Figure 3a). At end of RT the mean VAS values showed a response to therapy in both groups, albeit significantly lower in arm A after three and six months $(\mathrm{p}<.001)$ (Table 3). In arm B the pain symptoms worsened up to six months after RT, while in the intervention group the VAS values remained virtually constant (Figure $3 \mathrm{~b}$ ). It was not possible to discern any difference between the groups in terms of neuropathic pain.

In Arm A, complete response and partial response rates at 12 weeks were documented in $4.6 \%$ and $63.6 \%$, therefore $68.2 \%$ were responders $(\mathrm{p}=.172)$. After 6 months, $72.2 \%$ of patients were responders. Patients of control group showed a complete response and partial response at

Table 2 Results of OMED, VAS, and neuropathic pain

\begin{tabular}{|c|c|c|c|c|c|c|c|}
\hline \multirow[b]{2}{*}{ OMED } & \multicolumn{3}{|c|}{ Intervention group $(n=30)$} & \multicolumn{3}{|c|}{ Control group $(n=30)$} & \multirow[b]{2}{*}{ p-value } \\
\hline & $\mathbf{n}$ & Mean & SD & $\mathbf{n}$ & Mean & SD & \\
\hline Baseline (t0) & 30 & 56.8 & 132.2 & 30 & 45.0 & 86.2 & 0.841 \\
\hline RT completed (t1) & 30 & 43.8 & 88.7 & 30 & 50.7 & 88.7 & 0.452 \\
\hline After 3 months (t2) & 22 & 30.2 & 59.1 & 21 & 62.7 & 84.6 & 0.091 \\
\hline After 6 months (t3) & 18 & 20.8 & 46.9 & 18 & 76.7 & 103.6 & 0.018 \\
\hline \multicolumn{8}{|l|}{ Visual analog scale } \\
\hline Baseline (t0) & 30 & 48.2 & 20.5 & 30 & 51.3 & 26.9 & 0.393 \\
\hline RT completed (t1) & 30 & 23.8 & 20.2 & 30 & 33.3 & 24.6 & 0.118 \\
\hline After 3 months (t2) & 22 & 15.8 & 12.1 & 21 & 40.7 & 21.7 & $<0.001$ \\
\hline After 6 months (t3) & 18 & 16.7 & 14.8 & 18 & 50.3 & 22.8 & $<0.001$ \\
\hline \multicolumn{8}{|l|}{ Neuropathic pain } \\
\hline Baseline (t0) & 30 & 0.2 & 0.4 & 30 & 0.2 & 0.4 & 0.749 \\
\hline RT completed (t1) & 30 & 0.1 & 0.3 & 30 & 0.2 & 0.4 & 0.326 \\
\hline After 3 months (t2) & 22 & 0.2 & 0.4 & 21 & 0.2 & 0.4 & 0.619 \\
\hline After 6 months (t3) & 18 & 0.2 & 0.4 & 18 & 0.2 & 0.4 & 0.694 \\
\hline
\end{tabular}

VAS was measured from 0 to 100 with 0 indicating no pain at all and 100 indicating worst possible pain.

Abbreviations: SD standard deviation, OMED oral morphine equivalent dose, VAS visual analog scale. 
a

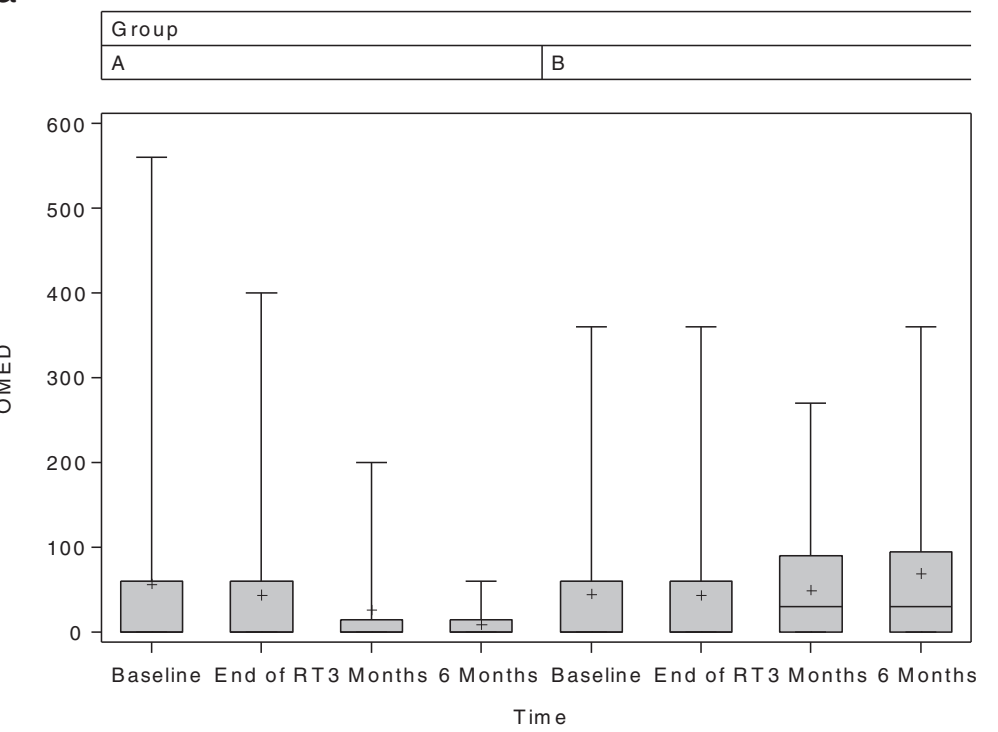

b

\begin{tabular}{|l|l|}
\hline Group & B \\
\hline A & P \\
\hline
\end{tabular}

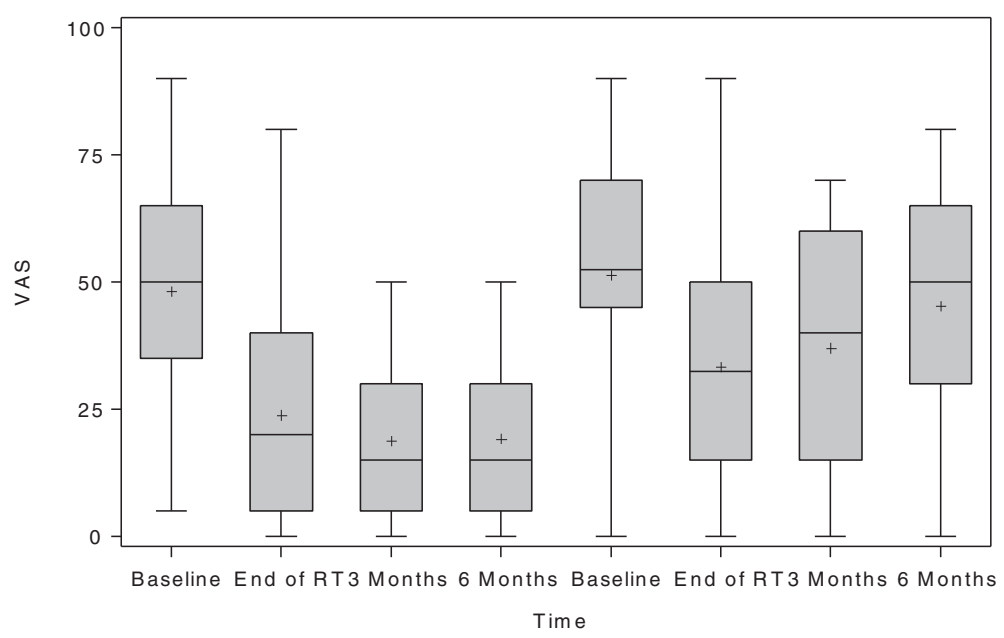

Figure 3 OMED and VAS of both groups at measured points. a. OMED of both groups at measured points (T0, T1, T2, T3). b. VAS of both groups at measured points (T0, T1, T2, T3).

12 weeks in $14.3 \%$ and $33.3 \%$, thus $47.6 \%$ were responders. The rate after 6 months was only $22.2 \%$ (Table 4 ).

\section{Discussion}

The vertebral column is the main localization of bone metastases and pain is the most frequently reported symptom of an advanced stage of a tumor disease. Palliative RT is an effective means for the treatment of pain in patients with bone metastases of the spinal column $[7,14]$ and will continue to remain the principal option for the treatment of painful bone metastases [15], with analgetics, systemic therapy, bisphosphonates, and minimal invasive surgery also playing their respective roles [7]. A non-pharmacological adjunctive therapy in the form of isometric training exercises of the autochthonous muscles has not yet been investigated and formed the basic concept of this novel pilot study.

Many other previously conducted studies have frequently used the pain response as the endpoint and presented this in the results. In most cases, a detailed report on the change in analgetics in the course of time was a weak point in the study design. The inclusion of the concomitant medication makes it possible to more exactly comprehend the therapeutic pain response to 
Table 3 Results of VAS, and concomitant medication during RT (day 1-10) and 12 weeks follow up

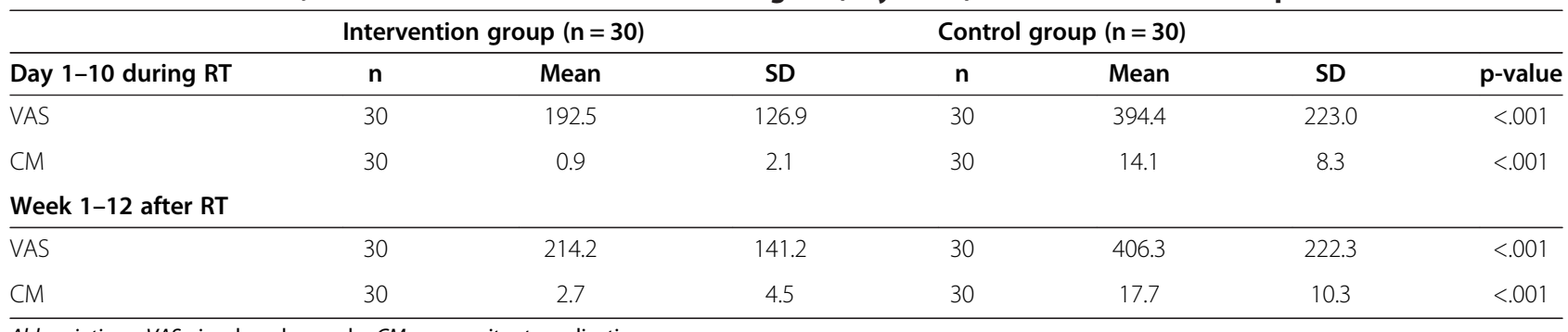

Abbreviations: VAS visual analog scale, CM concomitant medication.

RT. Our results demonstrated a more substantial pain reduction during $\mathrm{RT}$ in the intervention group, whereas in arm B the pain symptoms increased again until six months after RT. Analgesic medication, measured by OMED, remained constant up to the end of RT in both groups; in arm A the requirement for analgetic medication decreased until up to six months after RT, while it significantly increased again in arm B $(\mathrm{p}=.018)$. Also the requirement for pain medication in arm $\mathrm{A}$ was significantly lower both during and after RT $(\mathrm{p}<.001)$.

Previous clinical studies have shown that tumor patients can indeed profit from physical training measures during and following medical treatment $[4,16,17]$. A Norwegian study of 355 patients were the RT-related pain response rates significantly lower after 2 months, but the OMED increases from 40 to $60 \mathrm{mg}(\mathrm{p}<.001)$ [18]. This increase in OMED could also be seen in our control group.

Patients affected by this condition are usually immobilized, primarily due to the risk of pathological fractures and the related danger of spinal cord compression. In our study we were able to demonstrate the positive effect

Table 4 Results of pain response

\begin{tabular}{lccccc}
\hline & Intervention group & \multicolumn{4}{c}{ Control group } \\
\hline After 12 weeks & $\mathbf{n}$ & $\%$ & $\mathbf{n}$ & $\%$ & p-value \\
\hline CR & 1 & 4.6 & 3 & 14.3 & 0.196 \\
PR & 14 & 63.6 & 7 & 33.3 & \\
PP & 2 & 9.1 & 5 & 23.8 & \\
SP & 5 & 22.7 & 6 & 28.6 & \\
Responders & 15 & 68.2 & 10 & 47.6 & 0.172 \\
Non-responders & 7 & 31.8 & 11 & 52.4 & \\
After 6 months & & & & & \\
\hline CR & 4 & 22.2 & 3 & 16.7 & 0.049 \\
PR & 12 & 66.8 & 3 & 16.7 & \\
PP & 1 & 5.5 & 4 & 22.2 & \\
SP & 1 & 5.5 & 8 & 44.4 & \\
Responders & 13 & 72.2 & 4 & 22.2 & 0.014 \\
Non-responders & 5 & 27.8 & 14 & 77.8 & \\
\hline
\end{tabular}

Abbreviations: $C R$ complete response, $P R$ partial response, $P P$ pain progression, $S P$ stable pain. of a training regimen to strengthen the muscles of the back as an adjunct to RT in reducing pain. Optimal treatment of skeletal metastases is complex, and a multidisciplinary approach is often needed. Analgetics should be administered in order to control symptoms additional to palliative RT. Some patients with bone metastases manifest bone pain with distinguishable neuropathic features [19]. It was not possible to demonstrate a difference between the two groups regarding neuropathic pain components. Single and multiple fractionated RT doses were equally effective in the palliative treatment of pain and the functional impact on extra- and intraspinal localizations [20], which is why the fractionating is not specified in the protocol. In the literature, the response to therapy has so far generally been expressed on the basis of pain [21]. In their study in 160 patients, Foro et al. showed a complete and partial response in the 30 Gy arm in 13\% and $73 \%$ of the cases, respectively [13].

Chow et al. showed in their prospectively collected group of 518 patients the complete, partial, and overall response rates ranged from $21 \%$ to $25 \%, 26 \%$ to $30 \%$, and $46 \%$ to $50 \%$ [22]. These results correlate with our control group after three months. In another work, Chow et al. showed in a systematic review of 25 randomized controlled trials complete response rates of $23 \%$ in the single fraction arm and $24 \%$ in the multiple fraction arm [23]. Our study presented complete response rates in the intervention group after three and six months of $4.6 \%$ and $22.2 \%$, respectively, versus rates of $14.3 \%$ and $16.7 \%$, respectively, in the control group; these were lower in both arms, although after six months a considerable $72.2 \%$ versus $22.2 \%$ of the patients were responders.

The effects of resistance training became apparent and significant in reduced pain after six months, which suggests a higher benefit for survivors.

Because all patients are in advanced stages of their cancer, $40 \%$ of the patients in either group were lost to follow-up due to progressive disease and subsequent death. Further limitations of the study are the relatively small sample size, the variety of primary tumors and patient conditions, and the exclusion of patients presenting with cervical spine metastases. For feasibility reasons, patients' compliance with the training program in their 
homes was assessed only by relying on patient-completed documentation forms.

Among the strengths of the study are its randomized design and a relatively low drop-out rate, as well as standardized and specific measures to assess pain response among patients with bone metastases. This is, to our knowledge, the very first application of a resistance exercise program in patients with spinal metastases integrated in routine RT, to enhance their functional capacity and mobility, to reduce pain from spinal metastases.

\section{Conclusion}

In this group of patients we were able to show that guided isometric resistance training of the autochthonous muscles can improve pain relief over a 6-months period in patients with stable spinal metastases. Importantly, the intervention was able to reduce OMED as well as concomitant pain medication. This exercise is a promising and effective therapeutic approach to reduce pain to patients suffering from spinal metastases. Large controlled trials are necessary to confirm these findings.

\section{Competing interests}

The authors declare that they have no competing interests.

\section{Authors' contributions}

$H R$ and JD developed and planned this trial. TB is responsible for statistical considerations/basis of the analysis. GO, MA, and TW estimated the stability of bone metastases. HR, MK, SR, MH, and IS performed the examinations and RT supervisions. HR and AG made the data collection. HR performed the physical exercise. All authors read and approved the final manuscript.

\section{Acknowledgements}

The authors thank all of the study participants for their great effort. We acknowledge financial support by Deutsche Forschungsgemeinschaft and Ruprecht-Karls-Universität Heidelberg within the funding program Open Access Publishing.

\section{Author details}

'Department of Radiation Oncology, University Hospital of Heidelberg, Im Neuenheimer Feld 400, Heidelberg 69120, Germany. 'Department of Medical Biometry, University Hospital of Heidelberg, Im Neuenheimer Feld 305, Heidelberg 69120, Germany. ${ }^{3}$ Department of Orthopaedics and Trauma Surgery, University Hospital of Heidelberg, Schlierbacherstrasse 120a, Heidelberg 69118, Germany.

Received: 25 February 2014 Accepted: 30 June 2014

Published: 5 July 2014

\section{References}

1. Coleman RE: Metastatic bone disease: Clinical features, pathophysiology and treatment strategies. Cancer Treat Rev 2001, 27:165-176.

2. Harrington KD: Orthopedic surgical management of skeletal complications of malignancy. Cancer 1997, 80(8):1614-1627.

3. Janjan N, Lutz ST, Bedwinek JM, Hartsell WF, Ng A, Pieters RS Jr, Ratanatharathorn V, Silberstein EB, Taub RJ, Yasko AW, Rettenmaier A: Therapeutic guidelines for the treatment of bone metastasis: a report from the American College of Radiology Appropriateness Criteria Expert Panel on Radiation Oncology. J Palliat Med 2009, 12:417-426.

4. Hayes S, Spence R, Galvao D, Newton RU: Australian association for exercise and sport science potion stand: optimising cancer outcomes through exercise. J Sci Med Sport 2009, 12:428-434.

5. Mitera G, Probyn L, Ford M, Donovan A, Rubenstein J, Finkelstein J, Christakis M, Zhang L, Campos S, Culleton S, Nguyen J, Sahgal A, Barnes E, Tsao M, Danjoux C, Holden L, Yee A, Khan L, Chow E: Correlation of computed tomography imaging features with pain response in patients with spine metastases after radiation therapy. Int. J Radiation Oncol Biol Phys 2011, 81(3):827-830.

6. Wu JSY, Monk G, Clark T, Robinson J, Eigl BJ, Hagen N: Palliative radiotherapy improves pain and reduces functional interference in patients with painful bone metastases: a quality assurance study. Clin Oncol (R Coll Radiol) 2006, 18:539-544.

7. Chow E, Harris K, Fan G, Tsao M, Sze WM: Palliative radiotherapy trials for bone metastases: A systemic review. J Clin Oncol 2007, 25:1423-1436.

8. Knols R, Aaronson NK, Uebelhart D, Fransen J, Aufdemkampe G: Physical exercise in cancer patients during and after medical treatment: $\mathrm{A}$ systemic review of randomized and controlled clinical trials. J Clin Oncol 2005, 23:3830-3842.

9. Galvao DA, Newton RU: Review of exercise intervention studies in cance patients. J Clin Oncol 2005, 23:899-909.

10. Karnofsky DA, Burchenal JH: The Clinical Evaluation of Chemotherapeutic Agents in Cancer. In Evaluation of Chemotherapeutic Agents. Edited by MacLeod CM. New York: Columbia Univ Press; 1949:191-205.

11. Rief $H$, Jensen $A D$, Bruckner $T$, Herfarth $K$, Debus J: Isometric muscle training of the spine musculature in patients with spinal bony metastases under radiation therapy. BMC Cancer 2011, 11:482.

12. Chow E, Hoskin P, Mitera G, Zeng L, Lutz S, Roos D, Hahn C, van der Linden Y, Hartsell W, Kumar E: Update of the international concensus on palliative radiotherapy endpoints for future clinical trials in bone metastases. Int $\mathrm{J}$ Radiation Oncol Biol Phys 2012, 82(5):1730-7

13. Foro Arnalot $P$, Fontanals AV, Galcerán JC, Lynd F, Latiesas XS, de Dios NR, Castillejo AR, Bassols ML, Galán JL, Conejo IM, López MA: Randomized clinical trial with two palliative radiotherapy regimens in painful bone metastases: $30 \mathrm{~Gy}$ in 10 fractions compared with $8 \mathrm{~Gy}$ in single fraction. Radiother Oncol 2008, 89(2):150-5.

14. Klimo P Jr, Kestle JR, Schmidt MH: Clinical trials and evidence-based medicine for metastatic spine disease. Neurosurg Clin N Am 2004, 15:549-564

15. Lutz S, Berk L, Chang E, Chow E, Hahn C, Hoskin P, Howell D, Konski A, Kachnic L, Lo S, Sahgal A, Silverman L, von Gunten C, Mendel E, Vassil A, Bruner DW, Hartsell W: Palliative radiotherapy for bone metastases: An ASTRO evidence-based guideline. Int J Radiation Oncol Biol Phys 2011, 79(4):965-976

16. Maddocks M, Mockett S, Wilcock A: Is exercise an acceptable and practical therapy for people with or cured of cancer? A systemic review. Cancer Treat Rev 2009, 35(4):383-90.

17. Stevinson C, Fox KR: Feasibility of an exercise rehabilitation programme for cancer patients. Eur J Cancer Care 2006, 15:386-396.

18. Zaikova O, Fossa SD, Kongsgaard U, Kvaløy S, Giercksky KE, Skjeldal S: Pain after palliative radiotherapy for spinal metastases. Clin Oncol (R Coll Radiol) 2010, 22(10):828-36

19. Kerba M, Wu JSY, Duan Q, Hagen NA, Bennett MI: Neuropathic pain features in patients with bone metastases referred for palliative radiotherapy. J Clin Oncol 2010, 28:4892-4897.

20. Zeng L, Chow E, Zhang L, Culleton S, Holden L, Jon F, Khan L, Tsao M, Barnes E, Danjoux C, Sahgal A: Comparison of pain response and functional interference outcomes between spinal and non-spinal bone metastases treated with palliative radiotherapy. Support Care Cancer 2012, 20(3):633-9.

21. Nguyen J, Chow E, Zeng L, Zhang L, Culleton S, Holden L, Mitera G, Tsao M, Barnes $E$, Danjoux C, Sahgal A: Palliative response and functional interference outcomes using the Brief Pain Inventory for spinal bony metastases treated with conventional radiotherapy. Clin Oncol (R Coll Radiol) 2011, 23(7):485-91.

22. Chow E, Wu JS, Hoskin P, Coia LR, Bentzen SM, Blitzer PH: International concensus on palliative radiotherapy endpoints for future clinicla trials in bone metastases. Radiother Oncol 2002, 64(3):275-280.

23. Chow E, Zeng L, Salvo N, Dennis K, Tsao M, Lutz S: Update on the systematic review of palliative radiotherapy trials for bone metastases. Clin Oncol (R Coll Radiol) 2012, 24(2):112-124.

doi:10.1186/1471-2407-14-485

Cite this article as: Rief et al:: Pain response of resistance training of the paravertebral musculature under radiotherapy in patients with spinal bone metastases - a randomized trial. BMC Cancer $201414: 485$ 